\title{
AiMT
}

Advances in Military Technology

Vol. 11, No. 2 (2016), pp. 227-237

ISSN 1802-2308, eISSN 2533-4123

DOI 10.3849/aimt.01159

\section{Support for Protection of the Large Object Using UAVs}

\author{
M. Blišt'anová' ${ }^{*}$, J. Blažek ${ }^{1}$, P. Blišt'an ${ }^{2}$, J. Reitšpís ${ }^{1}$ and P. Havaj ${ }^{1}$ \\ ${ }^{1}$ University of Security Management in Košice, Slovak Republic \\ ${ }^{2}$ Faculty BERG, Technical University in Košice, Slovak Republic
}

The manuscript was received on 22 September 2016 and was accepted after revision for publication on 19 December 2016.

\begin{abstract}
:
The article represents a contribution to the protection of a specific object with a large perimeter in difficult terrain conditions. The introduction covers the complex issue of protection of objects as well as a justified usage of Unmanned Aerial vehicles (UAVs) with a camera as a potential technical element of the protection. The crucial part of the contribution is in the form of a specific case study for the purposes of protection and monitoring of the entrance of unauthorized persons into a dangerous area of a former mine. It is proven that the usage of UAVs is, or, more precisely, might be highly effective. However, the discussion points out some actual legislative issues related to using the UAVs equipped with cameras in relation to commercial, but mainly non-commercial, thus scientific-research activity in the context of the Slovak Republic.
\end{abstract}

\section{Keywords:}

UAV, monitoring, security, protection

\section{Introduction}

The aim of the protection of an object (a certain environment) is to create such an environment in which a subject is capable of achieving set objectives without any disturbing influences (life endangerment, loss, damage etc.). The objective is to create a stable and relatively foreseeable environment.

The awareness of the (security) state of the environment as a primary one represents the key concept for the draft of the object protection system [1].

In short, we can conclude that the objective of the protection is to create a safe environment in a (general) security environment by implementing security measures eliminating both external and internal impacts. Such a state can be expressed through the force field method, for instance (Fig. 1).

\footnotetext{
* Corresponding author: University of Security Management in Košice, Kukučinová 17, Košice, Slovak Republic.E-mail: monika.blistanova@vsbm.sk
} 


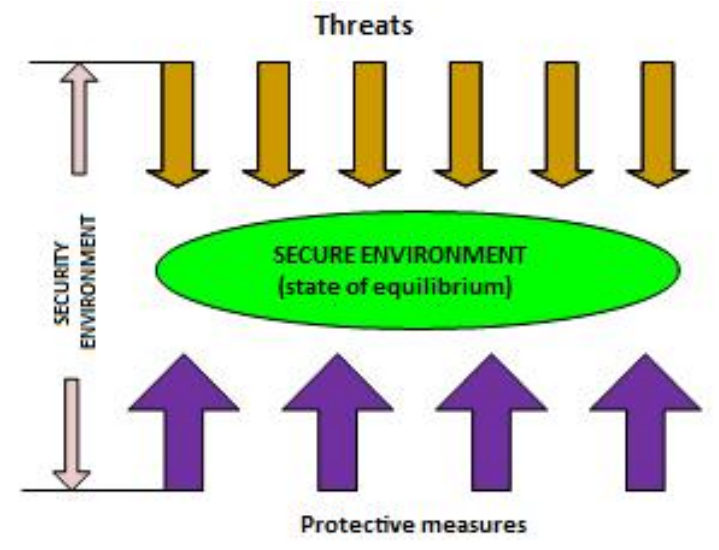

Fig. 1 The analysis of the force field in a security environment

To enable the system to function properly, the "value" of the security measures $\left(H_{\mathrm{oo}}\right)$ has to exceed the "value" of threats $\left(H_{\mathrm{H}}\right)$. The ratio of these values is expressed by the security coefficient, whereas it must be true that

$$
K_{\mathrm{B}}=\frac{H_{\mathrm{OO}}}{H_{\mathrm{H}}}>1 .
$$

The amount of the $K_{\mathrm{B}}$ coefficient can be defined depending on the importance of the protected element (object, environment etc.). The security measures' setting must be based on the following three essential questions and answers to them:

- What needs to be protected (the object to be protected, protected interests, ...).

- What it needs to be protected from (risks, damage, ...).

- How it needs to be protected (designing a security system, implementing security elements, ...).

The answer to the first question represents a thorough analysis of the protected interest in relation to its value to the subject (persons, life, health, movable assets, intellectual property, know-how, ...).

The second question assumes a complex analysis of risks which might potentially endanger the protected interest in a particular environment. The risk management is described in ISO 31000.

The third question is dealt with by implementing own protective measures into a particular environment in response to potential risks. Basically, we are talking about the following [1-3]:

- Designing mechanical guard means, such as building constructions, hole fillings, security deposit objects, lockable systems, security glasses or foils and other barriers (such as retarders, fences, ...).

- Designing technical means, alarm systems, including the intruder alarm system (IAS), close circuit television (CCTV), access control (AC) and fire detection system (FDS); other means, such as robotization, UAVs - drones, animals etc.

- Designing physical protection which can be categorized into the own protection (neighbourhood watches, for instance) and protection provided by security services which can be further divided into state and private ones.

- Designing regime measures. 
- Designing organizational measures.

The overall solution of the protection of objects is a result of the integration of all of the stages mentioned. The functionality of the system is also defined by the opportunity to gather, classify, process, evaluate, store and transfer relevant information within the desired time and space and in the desired quality. For this purpose, an information system shaping the bonds between its individual elements is applied in the protection system. To ensure the protection, the means are used in accordance with their designation and spatial organization of the object in individual zones. The perimeter protection, coat protection, spatial protection and subject protection are considered as the basic organization of elements. The key assumption of successful protection is balancing individual elements and respecting their aims in the protection system. Passive protection means serve to deter, slow down or, more precisely, stop the invaders, whereas active protection means serve to detect them subsequently. In special cases, the active protection means can also substitute the tasks of passive protection means. The physical protection means ensuring a timely intervention and arresting of the invader represent an inseparable part of the protection system. In order to meet the security policy objectives, as well as the actual protective measures, suitable organizational structures with defined superiority, inferiority, competences and duties are designed. The regime protection elements ensure correct and effective functioning of the already existing protective measures [1, 3].

In this article, we strive to point out the potentially effective usage of UAVs with a camera as a modern technical protection system element of a large object in a rugged terrain.

\subsection{Unmanned Aerial Vehicles}

UAVs have become a phenomenon of the $21^{\text {st }}$ century. The unmanned aerial vehicles equipped mainly with the cameras have begun to be utilized in an incredible range for the military, police, and rescue, geodetic, cartographic and also amateur purposes [4].

An unmanned aerial vehicle is a pilotless airplane that can be controlled by radio signal remote or fly autonomously based on flight path programmed or more complicated autonomous systems. UAV can carry many sensors such as GPS, compass, laser scanner and digital camera. With those sensors, it can be used in various missions in different fields [4].

Currently, the UAV devices are characteristic of some typical qualities [4-8]:

- A long flight time to gather a block of data.

- Long image sequences - hundreds to thousands of images.

- Navigation devices for automatic management of trajectory and orientation supported by the navigation based on a video.

- Stabilization of the platform for sensor carriers.

- Sensors for video navigation or range-based, modular or replaceable ones.

- Calibration of sensors and of the system.

- Ex-act geo-referencing of both hardware and software, direct or indirect georeferencing.

- Automatic image analyses and fast processing.

- Standard photogrammetric pre- and post-processing functions.

- 3D modelling of objects and processes (geometry and textures).

The today's market offers a relatively large number of UAVs differing in shape, size, lifting capacity, driving force, length, range, etc. The classification of drones 
through selected characteristics is therefore rather difficult. The UAV classification based on their characteristics is presented in Tab. 1.

Tab. 1. UAV classification based on selected properties [5, 7].

\begin{tabular}{ccccc} 
Category name & $\begin{array}{c}\text { Mass } \\
{[\mathbf{k g}]}\end{array}$ & $\begin{array}{c}\text { Range } \\
{[\mathbf{k m}]}\end{array}$ & $\begin{array}{c}\text { Flight Altitude } \\
{[\mathbf{m}]}\end{array}$ & $\begin{array}{c}\text { Endurance } \\
{[\boldsymbol{h}]}\end{array}$ \\
\hline Micro & $<5$ & $<10$ & 250 & 1 \\
\hline Mini & $<25 / 30 / 150$ & $<10$ & $150 / 250 / 300$ & $<2$ \\
\hline Close range & $25-150$ & $10-30$ & 3000 & $2-4$ \\
\hline Medium Range & $50-250$ & $30-70$ & 3000 & $3-6$ \\
\hline $\begin{array}{c}\text { High alt. Long } \\
\text { Endurance }\end{array}$ & $>250$ & $>70$ & $>3000$ & $>$
\end{tabular}

\section{Case Study - Mine Bankov Area, Košice, Slovak Republic}

In this paper, case study documents the basic possibilities of using UAVs to support the protection geographically extensive object with partially difficult terrain.

\subsection{Study Area}

The area studied is located in the residential area of the city of Košice, more specifically, in its north-western part and it directly borders with the urbanized part of the city (Fig. 2). It is a complex of currently unused mine premises where altogether 27 administrative and technical buildings, a photovoltaic power supply and old technical devices can be found. It is a large complex of 3277 square kilometres a with a rather rugged terrain and dangerous zones that emerged as a result of magnesite mining and processing (extraction shafts, ventilation shafts, entrances into the mining areas). The surroundings of the object are difficult to be controlled and along the periphery, they are surrounded by the following:

- Southern side: a gardening area, kitchen gardens.

- Northern side: forests, the Upper Bankov recreational area.

- Eastern side: a re-cultivated dam quarry after opencast mining, kitchen gardens.

- Western side: meadows and forests.

There are several access routes to the premises, most of them (except for the gate house with a ramp and the iron gate separating it from the recreational area of Upper Bankov) being unsecured, thus accessible for the public. The access routes are mainly of asphalt surface and in some cases those are only cart roads, their surface being unconsolidated. In winter, the access routes are not preserved and because of the ruggedness of the terrain, they are hardly usable for cars.

Currently, the perimeter protection of the whole object is represented by an incoherent fencing and an entry ramp at the gate house. The existing fencing often gets damaged by vandals, as well as by wild animals. The camera system has been built since 2002 and currently consists of 64 cameras. Its output can be found the central control station, on 6 monitors. The electronic protection system protects the internal areas of the buildings and technical objects. The physical protection is represented by 
the gatekeeper and the dispatcher operating at particular times. In case of such a large object, physical protections provided either by a security service or own protection is necessary.

The complex is mainly characteristic of its area, location and the presence of demonstration of old mining activities. The protection of the complex focuses not only on the protection of the protected interest, meaning selected buildings and the photovoltaic power supply, but also on the protection of people. Fans of adrenaline, homeless people and recreants shortening their paths through the complex from the recreational area to the city represent the biggest problem regarding the studied area. Not only are they causers of damages and thefts, but they also represent an endangered group that can either get injured or lost within the complex. Another problem of the complex are wild animals - mainly wild pigs, posing a threat to people moving within the premises predominantly at night, but also to the security services workers on night patrols. Because of that, it is necessary to monitor the place, both regularly and ad hoc, if needed.

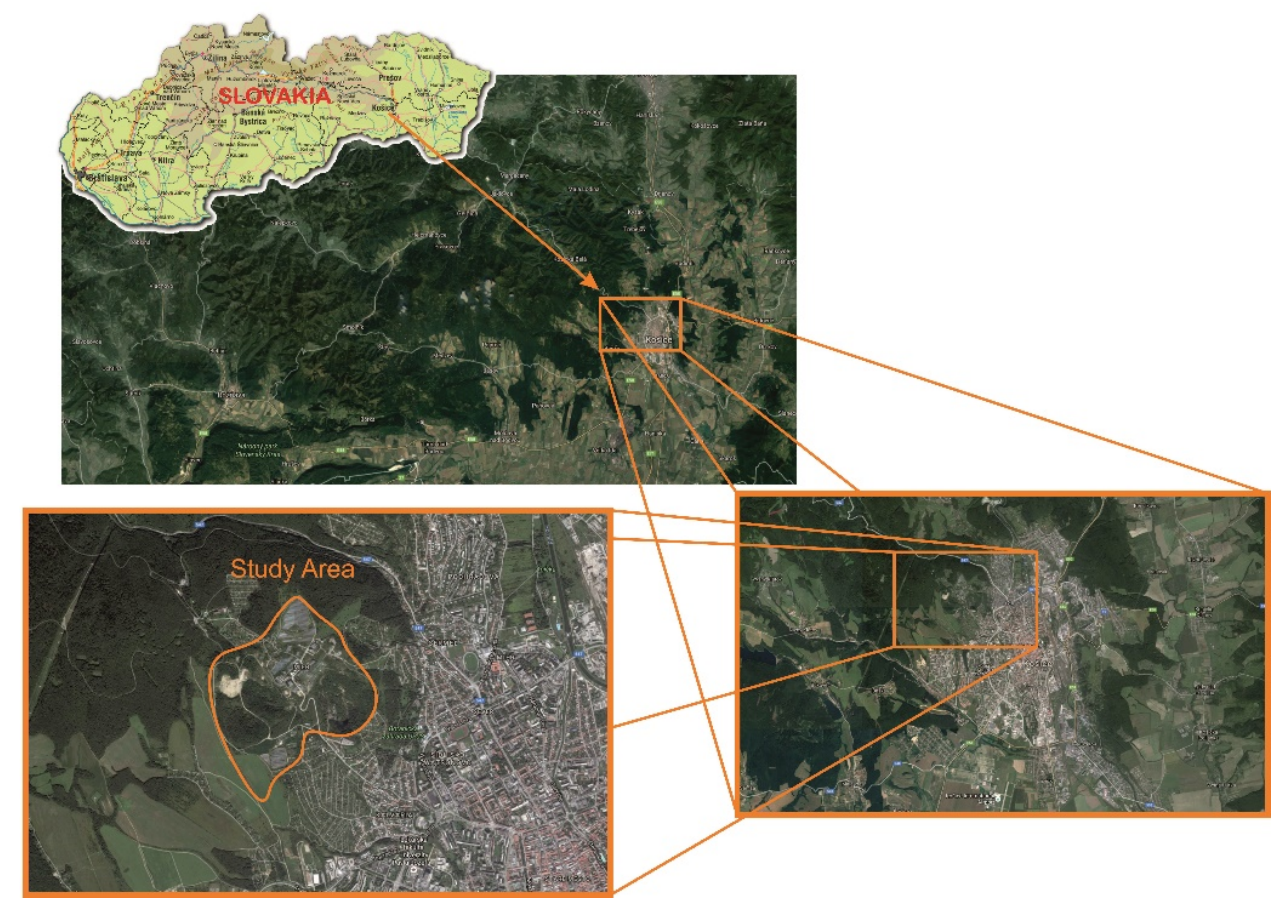

Fig. 1 Localization of study area

\subsection{Test}

For the experiment, the multicopter DJI Phantom 2 Vision + (Fig. 3) was used. This UAV equipment belongs to the category of “cheap" UAVs. It has a built-in GPS, a compass and a gyroscope DJI HD camera with a resolution of 14 megapixels. The camera is located on the 3-axial gimbal, which ensure its stability by three DC motors. 


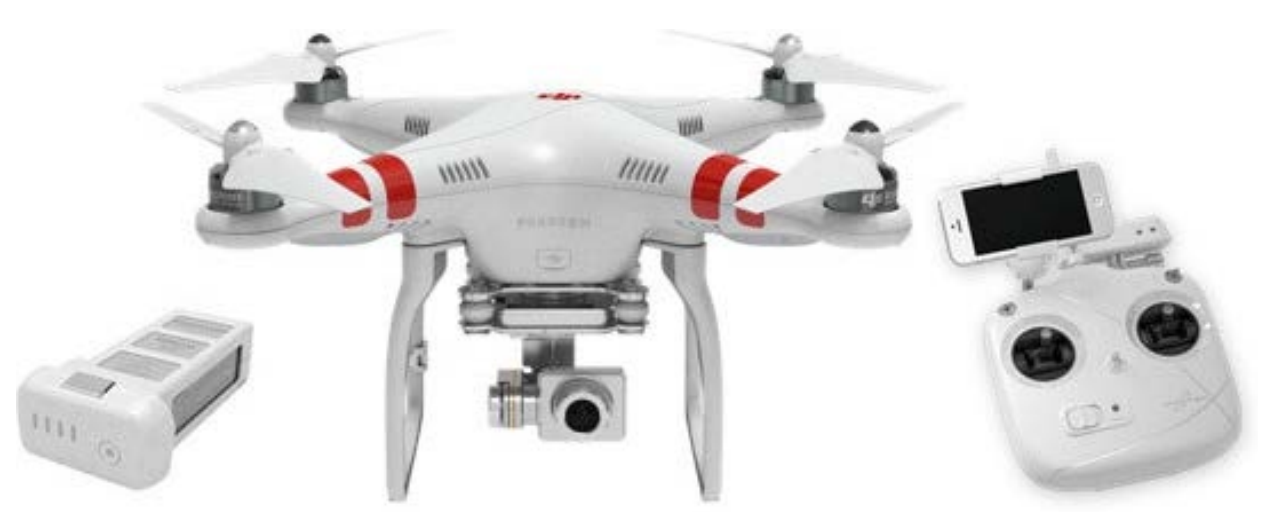

Fig. 3 Multicopter DJI Phantom 2 Vision+ [9]

The multicopter works in two modes. To stabilize the flight "GPS Atti Mode" was used. In this mode, the controller automatically stabilized multicopter in all axes. Based on using the control software working in an environment of Android, the flight plan was programmed. The flight lasted 15 minutes in total and it was created with 55 aerial photos. Technical parameters of the UAV are in Tab. 2.

In order to verify the usability of UAVs in the area of the Bankov mine, a mission the overall length of which was $1.3 \mathrm{~km}$ and which went over significant objects was planned. The objective of the mission was to monitor the following objects (Fig. 4):

- The collector field and the presence of persons within the internal perimeter protected by the fence.

- The fall area with displays of undermining in the form of a water area and the presence of persons within this dangerous area.

- The construction waste dumping site and the presence of unauthorized persons.

- Access routes and crossroads.

Tab. 2 Technical parameters DJI Phantom 2 Vision+ [9]

\begin{tabular}{|c|c|}
\hline \multicolumn{2}{|l|}{ Aircraft } \\
\hline Weight (Battery \& Propellers included): & $1242 \mathrm{~g}$ \\
\hline Max Ascent / Descent Speed: & $6 \mathrm{~m} \mathrm{~s}^{-1} / 2 \mathrm{~m} \mathrm{~s}^{-1}$ \\
\hline Max Flight Speed: & $15 \mathrm{~m} \mathrm{~s}^{-1}$ (Not Recommended) \\
\hline Diagonal motor-motor distance: & $350 \mathrm{~mm}$ \\
\hline \multicolumn{2}{|l|}{ Camera } \\
\hline Operating Environment Temperature: & $0^{\circ} \mathrm{C} \div 40^{\circ} \mathrm{C}$ \\
\hline Sensor size: & $1 / 2.3^{\prime \prime}$ \\
\hline Effective Pixels: & 14 Megapixels \\
\hline Resolution: & $4384 \times 3288$ \\
\hline Recording FOV: & $110^{\circ} / 85^{\circ}$ \\
\hline \multicolumn{2}{|l|}{ Remote Control } \\
\hline Communication Distance (open area): & $\begin{array}{l}\text { CE Compliance: } 400 \mathrm{~m} \\
\text { FCC Compliance: } 800 \mathrm{~m}\end{array}$ \\
\hline
\end{tabular}


The start of the mission was realized at the Ground Control Station (Fig. 4) located in the centre of the Bankov mine next to the Central Control Station building. The mission took 14 minutes and the UAV reached the borders of the interest area - the protected area.

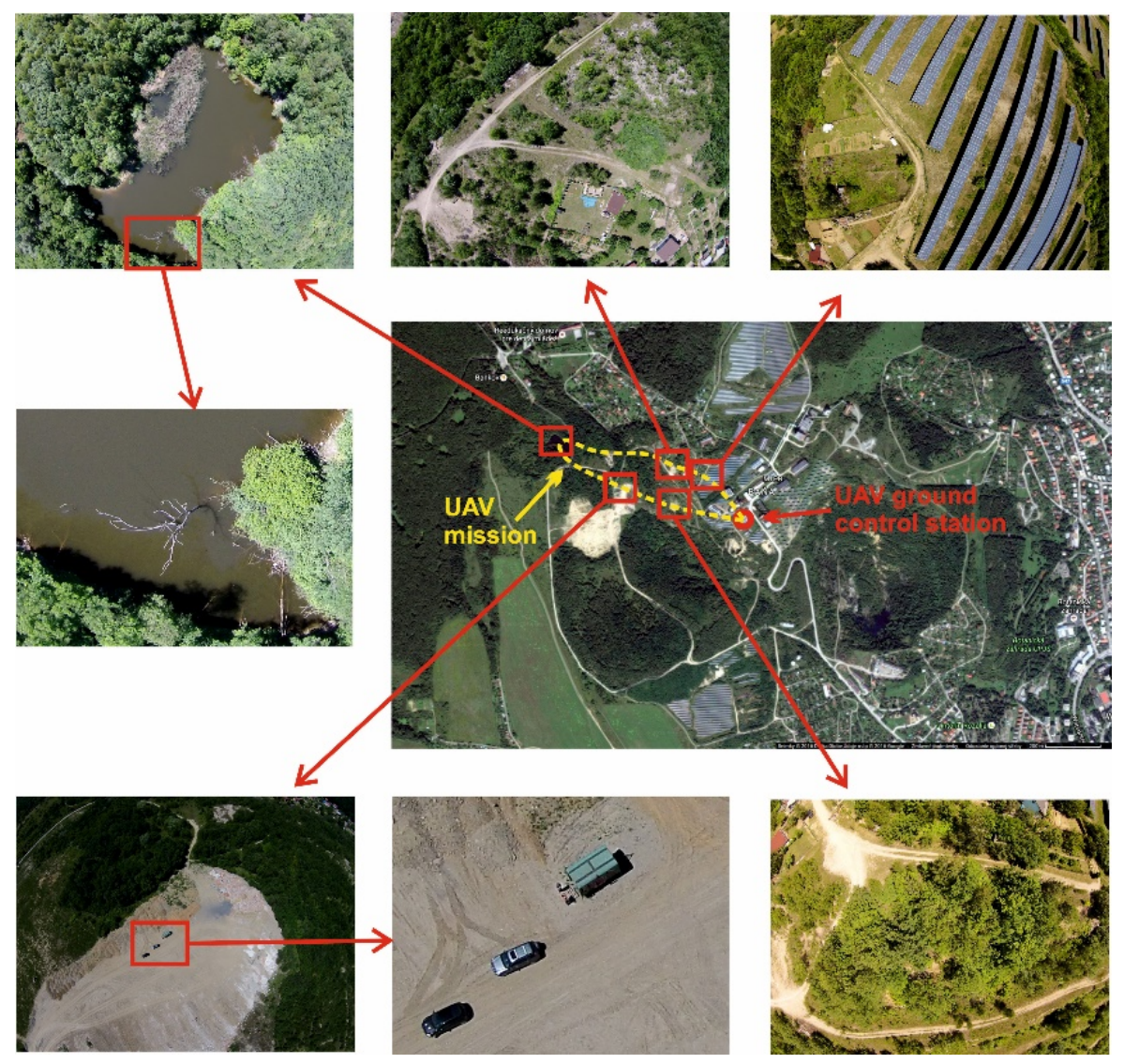

Fig. 4 The UAV Route During the Monitoring Mission

The results of the mission - pictures and videos - can be analysed either during the flight or later on. Fig. 5 portrays the identification of objects in one of the images obtained during the flight. In the detail in the centre-top, a fire is identified. With regard to the fact that on the top right in the picture, approximately $150 \mathrm{~m}$ from the fire, there is a part of the gardening area, it can be assumed that the fire was not made by the owners of the cottages. Considering the fact that homeless people and young people can be found in the area, such monitoring of fires, for instance, is important to identify the presence of these groups of invaders.

Provided the UAVs are equipped with an infra-red camera, monitoring is also possible at night. This way, it would be able to safely monitor the movement of invaders or wild animals from the height as the monitoring of the perimeter in a particular terrain by security services workers at night is rather problematic and the equipment with night vision cameras or day cameras with reflectors is impossible or ineffective for many reasons. 


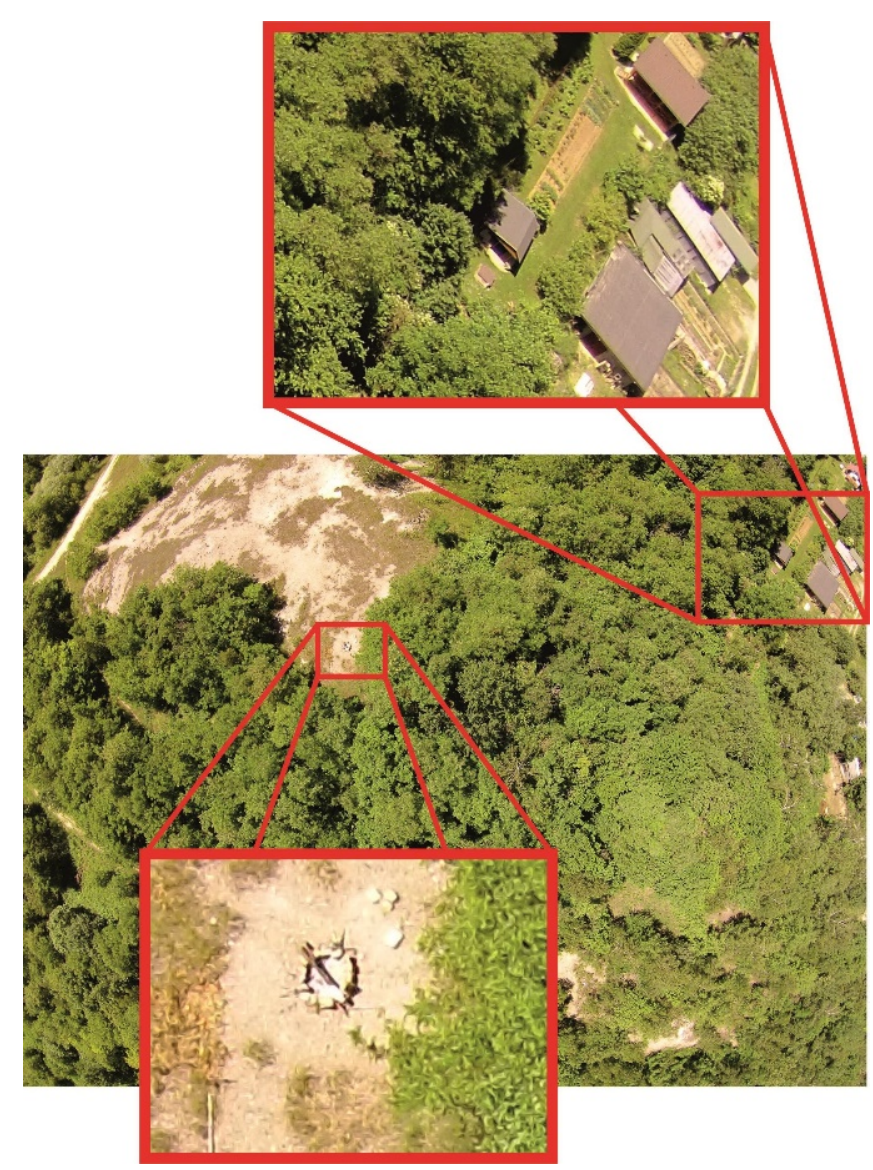

Fig. 5 Identification of Objects in Pictures Obtained During the Mission

\subsection{Test Results}

The protection of large objects is financially and technically difficult. In this case, the protection focuses on important objects; moreover, with regard to the character of the premises, the monitoring of areas which are problematic from the perspective of the inhabitants is necessary. The results have pointed out that it is effective to use UAVs to monitor large areas. The commonly available UAVs with the same parameters as our UAVs can be used to monitor the place during the day and in favourable weather conditions. Under these circumstances, it is possible to distinguish the presence of persons, cars or wild animals within the vicinity quite clearly. It is important to choose the right type of UAV; the choice should be based on the purpose of usage, the area and the character of the complex. It is also important to know whether the UAV shall be used to monitor regularly or just ad hoc. Another important question is whether the monitoring is also necessary to be done at night and whether there is a justifiable need for zooming the observed objects - for distinguishing whether it is an animal or an injured person. 
For the benefits of the use of drones in the area of objects, we can consider [5, 9]:

- safety in operations,

- programmatic flexibility,

- access to difficult areas and perspectives,

- economic cost,

- environmentally friendly: less noise, emissions, pollution, and disturbance.

Limiting factors are:

- legislative requirements,

- limitations in use in bad weather,

- specialist expertise required.

\section{Discussion}

This article shows that using drones equipped with cameras can be rather effective when protecting an object of large area. In this case, what is characteristic of the object is the fact that it is not the value of the protected interest which is low in case of majority of the area (a mining area after the exploitation was terminated) that is important, but what matters is to prevent unauthorized persons from entering the area for the sake of their safety. Any other solution to the control of the large perimeter and specific areas of the complex seems to be much more expensive and demanding.

In several countries, drones are used as an effective tool for the police and rescuers but also in other areas, such as e.g. the agriculture. However, since they got spread and used extensively with no rules, it has been proven that they have become a serious threat to the safety of people, air transport etc. That very quickly led to strict restraints, regulation of the flying conditions, required registration, qualification etc. The American Federal Aviation Administration (FAA) has been successfully dealing with this issue by publishing Part 107 [10] regarding the flying conditions which is continuously adjusted in order to allow to organize "reasonable" commercial and private aerial activities more often and simply compared to the originally strict restrictions, with regard to the protection of objects, too, for instance.

In the context of the Slovak Republic (SR), the Transport Authority published the decision No. 1/2015 effective since August 9, 2016 [11] that deals with the previously dangerous state (anarchy) in terms of the drone operation. In combination with the Law about sensitive intelligence of the SR, the part regarding taking photographs in the air [12], however, it is practically prohibited to use camera-equipped drones reasonably, including their use to protect private objects. In Slovakia, only 75 subjects have the permission to use them commercially, whilst their usage by the police and rescuers is specified neither in the flying rules nor in the list of subjects allowed the use of drones commercially. Except for the general prohibition to use cameraequipped drones, the non-commercial activity is not being dealt with, so working on exceptionally beneficial activities mainly within the range of the research of drone use for the purpose of environmental science, civil protection and protection of large areas (of one to tens of square kilometres) is, unfortunately, difficult.

To sum up, the status quo is dissatisfactory, yet in the SR, we shall wait for the new European Aviation Safety Agency rules valid for the whole Europe, the publishing of which is, compared to the rather flexible FAA, not foreseeable [13]. Yet a simple law adjustment defining an exception from taking photographs in the air for the owners of large objects (mining, industrial, agricultural) would be enough. So cameraequipped drones flying in altitude less $120 \mathrm{~m}$ could be used for the purposes of protec- 
tion, state exploration and situation analysis. Not to mention the fact that in times when Google Maps combined with satellite display are widely available along with the publicly available ZB GIS portal with ortophotomaps of the areas of Slovakia, the version of the law disabling the usage of camera-equipped drones for non-commercial activity (research, too) and making their commercial use difficult seems to be rather archaic. A reasonable solution is thus possible directly in the conditions of Slovakia, as the restrictions regarding cameras will, most probably, not be covered by the much expected European rules.

\section{Acknowledgement}

This contribution was created as part of VEGA project: Analysis of the possibilities of signal identification UAV in specific areas of interest. The number of project is: 1/0585/15.

\section{References}

[1] LOVEČEK, T. and REITŠPÍS, J. Design and evaluation system for the objects protection (in Slovak). Žilina: EDIS, 2011. 280 p.

[2] ŠČUREK, R. KONEČNÝ, M. and MARŠÁLEK, M. Extension of the solution protection of public universities premises via an implementation of radio frequency identification of people. Przeglad elektrotechniczny, 2014, p. 188-191.

[3] REITŠPÍS, J. Projecting security systems for the protection of objects. Košice: University of Security Management in Košice, 2015. 99 p.

[4] BLISTANOVA, M., BLISTAN, P. and BLAZEK, J. Mapping of surface objects and phenomena using Unmanned Aerial Vehicle for the purposes of crisis In Proceedings of the15th International Multidisciplinary Scientific GeoConference Surveying Geology and Mining Ecology Management. Sofia: STEF92 Technology, 2015, p. 491-500.

[5] EISENBEIB, H. UAV Photogrammetry [PhD Thesis]. Zürich, ETH Zurich, 2009. 203 p.

[6] KRŠÁK, B. et al. Use of low-cost UAV photogrammetry to analyze the accuracy of a digital elevation model in a case study. Measurement, ISSN 0263-2241, 2016, vol. 91, no. 1, p. 276-287.

[7] GREEN, DR. and GOMEZ, C. Small-Scale Airborne Platforms for Oil and Gas Pipeline Monitoring and Mapping [Research Report]. Aberdeen: University of Aberdeen, 2015. 54 p. [cited 2016-09-07]. Available from $<$ https://www.abdn.ac.uk/geosciences/documents/UAV_Report_Redwing_Final_ Appendix_Update.pdf>.

[8] WITAYANGKURN, A, NAGAI, M., HONDA, K., DAILEY, M. and SHIBASAKI, R. Real-time monitoring system using Unmanned Aerial Vehicle integrated with sensor observation service. International Archives of the Photogrammetry, Remote Sensing and Spatial Information Sciences, 2011, vol. 38, no. 1 , p. 107-112.

[9] DJI [on line]. Shenzhen: DJI. [cited 2016-09-07]. Available from: $<$ http://www.dji.com/phantom-2-vision-plus>. 
[10] FAA News. Small Unmanned Aircraft Systems (sUAS) (PART 107) [on line]. [cited 2016-09-07]. Available from: <https://www.faa.gov/uas/media/AC_1072_AFS-1_Signed.pdf>.

[11] Transport authority. Decision No. 1/2015 of 19/08/2015 Determining the Conditions for Carrying Out the Flight an Aircraft Is Fit To Fly Without a Pilot in the Airspace of the Slovak Republic (in Slovak) [on line]. DÚ/L001-A/v3, [cited 2016-09-07]. Available from:

<http://nsat.sk/wp-content/uploads/2014/08/DU_RPAS-merged.pdf>.

[12] Act No. 215/2004 Coll. on the Protection of Classified Information and on Amendments to Certain Acts [on line]. [cited 2016-09-07]. Available from: <http://www.noveaspi.sk/products/lawText/1/57952/1/2>.

[13] DSL. State Slightly Modify the Conditions for the Drones, Drones with Camera Still Forbidden to the Public (in Slovak) [on line]. August 2015, [cited 2016-0907]. Available from: <http://www.dsl.sk/article.php?article=17405>. 